\title{
The Framing of Speech Fluency in English as a Foreign Language (EFL) by In-Service Primary School Teachers
}

\author{
Oleksandr Kapranov ${ }^{1}$
}

\begin{abstract}
The article presents a mixed-method study of how in-service primary school teachers frame speech fluency in English as a Foreign Language (EFL). In the present study, a group of 19 in-service primary school teachers (further - participants) are asked to write reflective essays on the topic "My Understanding of Speech Fluency in EFL". The corpus of the participants' reflective essays has been contrasted with the reflective essays written on the same topic by a control group, which is comprised of 19 EFL pre-service primary school teachers. The results of the framing analysis reveal that the participants frame speech fluency in EFL by the frames Communication, Disfluency, Flow, Grammar, Importance, Multimedia, Role Model, Vagueness, and Vocabulary. Notably, there are qualitative and quantitative differences in the distribution of the frames between the groups of participants and controls. The results of the data analysis indicate that the distribution of the frames involves such variables as the approach towards speech fluency in EFL and the participants' view of their own speech fluency in EFL. Keywords: English as a Foreign Language (EFL), in-service teachers, primary school, speech fluency.
\end{abstract}

\section{[es] El encuadre de la fluidez del habla en inglés como lengua extranjera por parte de los maestros de escuela primaria}

Resumen. El artículo presenta un estudio de métodos mixtos sobre cómo los maestros de primaria en servicio enmarcan la fluidez del habla en inglés como lengua extranjera (EFL). A un grupo de 19 maestros de escuela primaria en activo (de ahora en adelante, "participantes") se les solicita que escriban ensayos reflexivos sobre el tema "Mi comprensión de la fluidez del habla en EFL". El corpus de los ensayos reflexivos de los participantes ha sido contrastado con los ensayos reflexivos escritos sobre el mismo tema por un grupo de control, compuesto por 19 maestros de primaria antes de prestar servicio activo de EFL. Los resultados del análisis revelan que los participantes enmarcan la fluidez del habla en EFL por los marcos Comunicación, Disfluencia, Flujo, Gramática, Importancia, Multimedia, Modelo de roles, Vaguedad y Vocabulario. En particular, existen diferencias cualitativas y cuantitativas en la distribución de los marcos entre los grupos de participantes y los controles. Los resultados del análisis de datos indican que la distribución de los marcos involucra variables tales como el enfoque hacia la fluidez del habla en lengua extranjera y la visión de los participantes de su propia fluidez en el EFL.

Palabras clave: inglés como lengua extranjera (EFL), maestros en servicio activo, escuela primaria, fluidez del habla.

Contents. 1. Introduction. 2. In-service efl teachers' reflections on speech fluency in efl/esl: literature review. 3. The present study. 3.1. The objectives of the study. 3.2. Participants. 3.3. Procedure, corpus and methods. 3.4. Results. 3.5. Discussion. 4. Conclusions.

1 Department of Language, Literature, Mathematics and Interpreting, Western Norway University of Applied Sciences, oleksandr.kapranov@hvl.no. 
How to cite this article: Kapranov, O. (2019) The Framing of Speech Fluency in English as a Foreign Language (EFL) by In-Service Primary School Teachers, in Complutense Journal of English Studies 27, 79-98.

\section{Introduction}

This article presents and discusses a mixed-method study that seeks to investigate how in-service primary school teachers of English as a Foreign Language (EFL) frame speech fluency in the English language. The study aims to identify and examine a possible range of frames that construe the in-service EFL primary school teachers' view of speech fluency in EFL. The study is embedded into the notions of framing (Pennington 1999; Pennington \& Hoekje 2014) and speech fluency in a foreign language (Chambers 1997; Götz 2013; Kormos 2014; Kormos \& Dénes 2004; Lennon 1990; Rossiter et al. 2010; Sato 2014; Tavakoli \& Hunter 2018).

Framing refers to "the process by which people develop a particular conceptualization of an issue or reorient their thinking about an issue" (Chong \& Druckman 2007: 104). According to Entman (1993), framing involves the selection of certain features of reality in order to

make them more salient in a communicating text, in such a way as to promote a particular problem definition, causal interpretation, moral evaluation, and/or treatment recommendation for the item described. Typically frames diagnose, evaluate, and prescribe... (Entman 1993: 52)

Following Entman (1993), framing is defined as the interlocutor's knowledge that "(i) concerns a particular aspect of the world, (ii) generates expectations and inferences in communication and action, and (iii) tends to be associated with particular lexical and grammatical choices in language" (Semino, Demjén, \& Demmen 2016: 627). In concert with Entman (1993), Chong and Druckman (2007) indicate that framing allows to view an issue from a variety of perspectives that involve implications for multiple values or considerations of the issue (Chong \& Druckman 2007: 104). Similarly, Burgers, Konijn, and Steen (2016) posit that framing is comprised of explicit linguistic structures and the implicit information in a text that are used in the presentation of a problem, its cause, evaluation, and its possible treatment (Burgers, Konijn, \& Steen 2016: 410). From a discursive perspective, framing is associated with a discursive space that "offers a range of different constructions of the speech event in terms of such characteristics as participant roles and relationships, topics, and forms of language" (Pennington 1999: 53).

Framing is widely employed in applied linguistics (Pennington 1999; Pennington \& Hoekje 2014), cognitive linguistics (Fillmore 2006), education and pedagogy (Bernstein 2018). Whilst framing is regarded as a mental operation and a system of inter-related concepts in cognitive linguistics (Fillmore 2006), in education and pedagogy framing is operationalised as a process of selection, classification, distribution, transmission, and evaluation of the educational knowledge in any society (Bernstein 2018: 365), culture, and/or sociocultural contexts. From the perspective of applied linguistics, for instance, framing is used to discuss sociocultural contexts. In particular, Pennington (1999) elaborates upon several frames that are involved 
in a bilingual sociocultural discursive space, for example, Lesson, Lesson Support, Institutional Support, and Commentary frame. Pennington (1999) argues that the frame Lesson is comprised of communicative and educational activities in the English language in the bilingual classroom. The frame Lesson Support is connected to the frame Lesson via the discursive role of the teacher and the secondary roles of ESL students. The frame Institutional Support involves discursive input from school as an institution. The Commentary frame is argued to be on the periphery of the bilingual classroom's communication.

Pennington and Hoekje (2014) suggest that EFL can be analysed as a set of frames depending on whether or not EFL involves the process of teaching, a service, or a teaching profession. According to Pennington and Hoekje (2014), the framing of EFL teaching is determined by socio-cultural contexts that give rise to Internal frames (e.g., EFL teachers) and External frames (e.g., school as a social institution). Other frames that are associated with EFL teaching are Work frames and Sociocultural Context frames. Work frames involve "different ways in which ELT work can be characterized" (Pennington \& Hoekje 2014: 164). Sociocultural Context frames reflect the activities of EFL learners, teachers, researchers, and administrators. The socio-cultural characteristics of these individuals play "a central role in creating the character of English language teaching in its different aspects" (Pennington \& Hoekje 2014: 165).

Concurrently with framing, speech fluency is another key notion in the present article. Speech fluency in the speaker's first language (L1) is theorised to involve "a smooth "flow" from one word or thought to the next, a reasonable speech rate, and few production errors or speech fillers ..." (James, Chambers, \& Placzek 2018: 520). It is argued that speech fluency is "related to how sequential, prosodic aspects of pronunciation are managed to maintain the easy flow of connected speech with minimal gaps and disruptions (Pennington \& Rogerson-Revell 2019: 151). However, speech fluency in the speaker's second language (SL) and/or foreign language (FL) acquisition exhibits different characteristics due to the level of FL/SL language mastery in the speaker's speech production (Pinget et al. 2014). In FL and EFL settings, speech fluency is frequently contrasted with the learner's accuracy in speech output (Chambers 1997: 535). From the vantage point of EFL acquisition, speech fluency is viewed as "a performance phenomenon of implicit or procedural linguistic knowledge" (Sato 2014: 81).

Whilst the definition of speech fluency varies depending on the researcher and the research paradigm (Götz 2013; James, Chambers, \& Placzek 2018; Rossiter et al. 2010; Tavakoli \& Hunter 2018), speech fluency in FL/EFL settings is usually defined in terms of the learner's near-native proficiency that involves "an excellent grasp of the vocabulary and grammar of a language" (Rossiter et al. 2010: 584). Traditionally, speech fluency is seen as an index of an EFL learner's proficiency (Kormos 2014; Lennon 1990; Sato 2014; Tavakoli 2010; Tavakoli \& Hunter 2018). In this regard, Bosker and the colleagues (2012) suggest that an EFL learner's speech fluency is "an important measure in assessing a person's language proficiency" (Bosker et al. 2012: 159). This observation is echoed by Tavakoli and Hunter (2018), who argue that speech fluency in an FL is one of the descriptors of speech production. From the perspective of language proficiency, speech fluency is considered to be indicative of an EFL learner's complexity in the English language (Lennon 1990; Tavakoli \& Hunter 2018: 331). 
In addition to being a descriptor of the learner's language proficiency, speech fluency is typically approached from the so-called broad and narrow perspectives (Lennon 1990). The broad perspective is associated with error-free grammar and the correct use of syntactic features, a substantial vocabulary and lexical diversity, native-like accent and intonation, idiomaticity and the use of pragmatic features (Bosker et al. 2012; Götz 2013). According to Chambers (1997), speech fluency "in the broad sense is equivalent to overall speaking proficiency" (Chambers 1997: 536). Seen from the broad perspective (Lennon 1990), speech fluency in EFL has been associated with a certain degree of automaticity on the part of an EFL learner (Segalowitz \& Freed 2004). The automaticity of speech fluency in EFL, or in any FL, involves the automatisation of lexical retrieval, the proceduralisation of grammar and articulation skills (Segalowitz \& Freed 2004), and the availability of routinised linguistic knowledge (Bergman et al. 2015: 25).

In contrast to the broad perspective, there is a narrow approach towards speech fluency. The narrow approach is thought to be associated with smoothness (Lennon 1990) and the speed of speech delivery (Tavakoli 2010). The narrow approach is exemplified by "the ability to talk at length with few pauses, the ability to fill time with talk" (Fillmore 1979: 51). From the vantage point of the narrow approach, speech fluency is regarded as an 'impression on the listener's part that the psycholinguistic processes of speech planning and speech production are functioning easily and smoothly" (Lennon 1990: 391).

Whilst EFL students' speech fluency has been sufficiently researched from the broad and narrow perspectives (Bosker et al. 2012; Kormos 2014; Kormos \& Dénes 2004; Lennon 1990; Tavakoli \& Hunter 2018), currently there are limited studies that involve speech fluency in EFL seen through the lenses of EFL in-service primary school teachers. Moreover, little is known about the framing of speech fluency in EFL by those in-service EFL primary school teachers, who are enrolled in in-service EFL teacher training courses. The novelty of the study further described and discussed in the article rests with the investigation of the framing of speech fluency in the English language by a group of in-service EFL primary school teachers (further - participants), who are enrolled in the in-service EFL teacher training course that is specifically designed to allow the participants to combine their work at primary schools with the study of English on the tertiary level. Since the participants teach EFL at their respective schools and simultaneously attend the in-service EFL teacher training course, their teacher identities reflect a combination of selves that involve a teacher identity, a university student identity, and, presumably, an amalgamation of the above-mentioned identities (Safari 2018). Arguably, this unique combination of the participants' experiences could map onto a specific framing of speech fluency in EFL.

The participants' framing of speech fluency in EFL is investigated in the present study by means of the framing analysis of the participants' reflective essays on the topic "My Understanding of Speech Fluency in EFL". In the study, the corpus of the participants' essays is juxtaposed with the corpus of reflective essays written on the same topic by the control group, comprised of the pre-service EFL primary school teachers. Further, this article is structured as follows. First, a review of prior research literature on EFL teachers' reflections on EFL speech fluency is provided in section 2 of the article. Second, the present study is outlined and discussed in section 3. Finally, linguo-didactic implications are given in the conclusions in section 4 . 


\section{In-service efl teachers' reflections on speech fluency in efl/esl: literature review}

As previously mentioned in the introduction, there are no prior studies that examine speech fluency in EFL through the lenses of the framing methodology. However, there is a substantial body of research that addresses the issue of speech fluency by means of examining in-service teachers' reflections (Butler 2004; Fuchs, Kahn-Horwitz, \& Katzir 2019; Tavakoli \& Hunter 2018; Saito \& van Poeteren 2012; Yang 2014). These studies investigate EFL/ESL teachers' reflections on speech fluency in EFL/ESL contexts in China (Yang 2014), Israel (Fuchs, Kahn-Horwitz, \& Katzir 2019), Japan (Saito \& van Poeteren 2012), Korea and Taiwan (Butler 2004), and the UK (Tavakoli \& Hunter 2018). In particular, Tavakoli and Hunter (2018) seek to explore how ESL teachers define speech fluency in ESL and how they promote speech fluency in an ESL classroom. Using a questionnaire administered to 84 ESL in-service teachers, Tavakoli and Hunter (2018) have found that the participants in the study define speech fluency in the broad sense. Whilst the broad understanding of speech fluency is prevalent amongst the participants, it is posited by Tavakoli and Hunter (2018) that the adoption of a narrow approach towards speech fluency by the participants would facilitate "a more active and practical approach to promoting fluency in the classroom" (Tavakoli \& Hunter 2018: 330). Arguably, their findings reveal a complex and dynamic nature of speech fluency in ESL settings.

The study by Yang (2014) is set in the EFL context in China, where 10 experienced EFL teachers reflect upon their willingness to facilitate speech fluency in an EFL classroom. Additionally, the participants in the study (Yang 2014) are asked to reflect and rate their communicative strategies of speech fluency in their oral classroom communication with EFL students. Yang's (2014) findings indicate that the participants appear to ignore speech fluency in their EFL interaction with the students. Yang (2014) argues that the findings are suggestive of the epiphenomenal role of speech fluency in EFL on the part of the participants.

Saito and van Poeteren (2012) seek to explore how 120 experienced EFL teachers in Japan rank pronunciation features that they deem to be important for their students to achieve intelligible pronunciation. The study by Saito and van Poeteren (2012) has revealed that the participants seem to prioritise the correct pronunciation of individual English sounds and suprasegmentals as a token of EFL learners' proficiency. It appears that the participants in Saito and van Poeteren (2012) consider EFL speech fluency an epiphenomenal variable in teaching and learning pronunciation in English (Saito \& Poeteren 2012: 374).

In Butler (2004), speech fluency is regarded concurrently with other variables involved in EFL proficiency and teaching skills. The study conducted by Butler (2004) involves a cohort of EFL teachers from Japan, South Korea, and Taiwan. The participants in the study self-assess their English proficiency and suggest the level of EFL proficiency that is required to teach EFL at primary school. Butler (2004) has discovered a substantial gap in the participants' proficiency in the English language. According to Butler (2004), the areas of concern are associated with the participants' productive skills and speech generation in EFL. In particular, the participants indicate that their speech fluency in English needs improvement (Butler 2004). Specifically, there is a gap between the current level of the participants' speech fluency in 
English and the desired level of speech fluency that the participants deem necessary to be able to teach at primary school.

Fuchs, Kahn-Horwitz, and Katzir (2019) investigate what 167 Israeli EFL primary school teachers think about reading fluency. Fuchs, Kahn-Horwitz, and Katzir (2019) argue that "Fluency is the ability to read texts quickly, effortlessly and with meaningful expression" (Fuchs, Kahn-Horwitz, \& Katzir 2019: 1). The authors suggest that reading fluency is a robust predictor of reading ability (Fuchs, Kahn-Horwitz, \& Katzir 2019). It has been found in the study by Fuchs, Kahn-Horwitz, and Katzir (2019) that the participants recognise the important role of fluency in reading in EFL.

It is evident from the literature review that whilst there are previous studies that involve in-service teachers' reflections on speech fluency in EFL/ESL, there is insufficient research that applies framing and framing methodology to construe speech fluency in EFL. The study further described in this article seeks to identify the framing of speech fluency in EFL by a group of participants, who combine a dual role of being in-service EFL primary school teachers and university students in an EFL course for in-service teachers.

\section{The present study}

The present study is contextualised within an in-service EFL teacher training course that is offered at a large university in Norway. The course duration is two semesters, and it involves three in-mural teaching sessions each semester. This course design allows the participants to teach full-time concurrently with being enrolled in the course. The course consists of such modules, as functional grammar, phonetics, and children's literature. The course in English phonetics follows the topics described in the course book English Phonetics for Teachers by Nilsen and Rugesæter (2015), for instance, Sound Foundation, Consonants, Vowels, Stress, Rhythm, and Sounds in Company, Intonation, Teaching Pronunciation, and The Varieties of Spoken English.

In the context of this study, it is essential to specify the current role of speech fluency in EFL in Norwegian primary schools. In Norway, speech fluency in EFL teaching and learning is regarded within the parameters that are set by the Council of Europe's Common European Framework of Reference for Languages: learning, teaching, assessment (Council of Europe 2001; Simensen 2010). However, recent research suggests that the role of speech fluency in EFL in Norwegian primary schools seems to be de-emphasised (Torgersen 2018: 215-216). Whilst the importance of speech fluency is not contested in EFL teaching and learning in Norway (Torgersen 2018), it should be mentioned that speech fluency "was for a long time left out of the syllabuses in the Norwegian school system" (Simensen 2010: 6).

\subsection{The objectives of the study}

The objectives of the study are based upon an assumption that the participants' enrollment in the in-service EFL course and their concurrent EFL teaching at primary schools are facilitative of the creation of a particular combination of experiences that, arguably, map onto the participants' specific framing of speech fluency in EFL. 
Following this assumption, the present study seeks to identify and examine a possible range of frames that construe the participants' view of speech fluency in EFL. The specific research objectives of the study are as follows,

i) to identify the participants' framing of speech fluency in EFL;

ii) to examine whether or not the participants' framing of speech fluency in EFL is reflective of the broad or narrow approaches to speech fluency;

iii) to juxtapose the participants' framing with that of the control group, comprised of pre-service EFL primary school teachers.

\subsection{Participants}

In total, the study involves 19 participants ( 17 females and 2 males, mean age $=42$ y.o., standard deviation =9). All participants indicate that English is their FL and Norwegian is their L1. There are no bilinguals amongst the participants. The participants are enrolled in the in-service EFL course at a large university in Norway. Their enrollment in the course is concurrent with full-time employment as teachers at a range of primary schools. All participants are college-educated primary school teachers (mean duration of teaching experience $=11$ years, standard deviation $=4$, 4). Based upon the self-evaluation reports, $32 \%$ of the participants describe themselves as fluent, while $68 \%$ self-assess their level of speech fluency in the English language as average. According to the participants, the mean age of becoming fluent in English is 17 y.o. (standard deviation =2).

The control group is comprised of 19 pre-service EFL teachers (14 females and 5 males) enrolled in the teacher training programme at the same university as the participants. The controls' mean age is 24 y.o. (standard deviation $=6$ ). Judging from the self-assessment data, the controls' mean age of becoming fluent in English is 15 y.o. (standard deviation $=3$ ). $79 \%$ of the controls evaluate their level of speech fluency in English as fluent, and 21\% indicate that it is average. Similarly to the participants, there are neither native speakers of English nor bilinguals amongst the controls. The controls attend a university course in English phonetics and follow the same course book in English phonetics as the participants do.

The participants and their respective controls have signed the consent form allowing the author of the present article to collect and analyse their written data for scientific purposes. The participants' and controls' data are coded to ensure confidentiality so that no personal information is disclosed. The participants in the study are coded as P and the number, e.g. P1, P2, P3 ... P19. The same coding procedure is applied to the control group, and the controls are coded as C1, C2, C3 ...C19, respectively.

\subsection{Procedure, corpus and methods}

The following procedure was used in the study: the participants (and in the separate session, the control group) were asked by the author of the article to write a reflective essay of approximately 1000 words on the topic "My Understanding of Speech Fluency in EFL". The participants and controls received instructions that they had two weeks to write their essays at home. It was explicitly communicated to the participants and their respective controls that they were allowed to use the course book 
in phonetics and peer-reviewed scientific sources from scholar.google that dealt with speech fluency in EFL. To facilitate the writing of the essay, the participants and controls were offered a scaffolding that involved the following questions:

Paragraph 1. What is your own understanding of the term "speech fluency" in EFL?

Paragraph 2. How would you evaluate your own speech fluency in EFL?

Paragraph 3. When do you think you became fluent in English?

Paragraph 4. What is the role of fluency in EFL in your life?

Paragraph 5. What is the role of fluency in EFL in the lives of your primary school students?

However, the participants and controls were instructed that the scaffolding could be modified and/or ignored, if necessary. The participants' and controls' reflective essays were analysed by means of the computer software program WordSmith (Scott 2008) in order to calculate the most frequent words. Additionally, the software program Statistical Package for Social Sciences (SPSS) was used to calculate means and standard deviations of the essay corpus per group (see Table 1 below).

Table 1. Descriptive Statistics of the Corpus.

\begin{tabular}{|c|l|l|l|}
\hline N & \multicolumn{1}{|c|}{ Measure } & \multicolumn{1}{c|}{ Participants } & \multicolumn{1}{c|}{ Controls } \\
\hline 1 & Total number of essays per group & 19 & 19 \\
\hline 2 & Total number of words & 20504 & 18869 \\
\hline 3 & $\begin{array}{l}\text { Mean (M) words and standard } \\
\text { deviation (STD) }\end{array}$ & $\mathrm{M}=1080(\mathrm{STD}=183)$ & $\mathrm{M}=993(\mathrm{STD}=104)$ \\
\hline 4 & Range of words (min. - max.) & $742(\min )-.1491(\max )$. & $777(\min )-$.1205 (max.) \\
\hline 5 & $\begin{array}{l}\text { Mean (M) paragraphs and standard } \\
\text { deviation (STD) }\end{array}$ & $\mathrm{M}=7,4(\mathrm{STD}=2,2)$ & $\mathrm{M}=6,8(\mathrm{STD}=2)$ \\
\hline 6 & Range of paragraphs (min. - max.) & 4 (min.) $-11(\max )$. & 3 (min.) -10 (max.) \\
\hline
\end{tabular}

The framing analysis was applied to the corpus of the participants' and controls' reflective essays in accordance with the procedure developed by Dahl (2015). Following Dahl (2015), the corpus was manually investigated for keywords, recurrent phrases, stereotyped expressions, and sentences that provided thematically reinforcing clustering. Then, the manual procedure was verified by means of employing the computer-assisted count of the most frequent words in the corpus in software program WordSmith (Scott 2008). Thereafter, the corpus was manually examined for the presence of adjectives associated with attitudes, feelings, and values used to construe attitudes, engagement, and intensity (see Dahl 2015). The frequency of those adjectives was verified by means of the computer-assisted count of the frequently used words in WordSmith (Scott 2008). Figure 1 below illustrated the frequency by providing a number of examples of the frequent adjectives in the corpus. 




Figure 1. The Most Frequent Adjectives in the Corpus.

Judging from the data presented in Figure 1, the participants associated speech fluency in EFL with such frequent adjectives, as English, fluent, good, important, and oral. They were matched with the frequency of the recurrent words and expressions in the sentences that provided thematically reinforcing clustering in corpus in order to arrive at the identification of the frames. Each frame was labelled in accordance with the frequency of the nouns that were used to convey domains, such as, for example, vocabulary $(\mathrm{N}$ occurrence $=37)$, communication $(\mathrm{N}$ occurrence $=21)$, gram$\operatorname{mar}(\mathrm{N}$ occurrence $=24)$, etc.

\subsection{Results}

The application of the framing analysis has yielded several qualitatively different frames used by the participants to construe their understanding of speech fluency in EFL. The participants appear to frame speech fluency in EFL by means of the frames Communication, Disfluency, Flow, Grammar, Importance, Multimedia, Role Model, Vagueness, and Vocabulary. The controls' framing of speech fluency in EFL involves such frames, as Communication, Disfluency, Flow, Grammar, Importance, Multimedia, and Vocabulary. The results of the data analysis indicate that the distribution of the frames is different between the groups of participants and their respective controls. In addition, the distribution of the frames depends on how the participants and controls frame i) speech fluency in EFL in general, ii) their own speech fluency in EFL, and iii) speech fluency of EFL primary school students. The quantitative distribution of the frames that are associated with speech fluency in EFL, in general, is summarised in Table 2 below. 
Table 2. The Quantitative Distribution of Frames Associated with Speech Fluency in EFL.

\begin{tabular}{|c|l|c|c|}
\hline $\mathbf{N}$ & \multicolumn{1}{|c|}{ Frame } & Participants & Controls \\
\hline 1 & Communication & $16 \%$ & $53 \%$ \\
\hline 2 & Disfluency & $11 \%$ & $5 \%$ \\
\hline 3 & Flow & $32 \%$ & $16 \%$ \\
\hline 4 & Grammar & $16 \%$ & $5 \%$ \\
\hline 5 & Importance & $26 \%$ & $21 \%$ \\
\hline 6 & Vagueness & $21 \%$ & - \\
\hline 7 & Vocabulary & $21 \%$ & $16 \%$ \\
\hline
\end{tabular}

The distribution of the frames that refer to the participants' and controls' own speech fluency in EFL is summarised in Table 3.

Table 3. The Framing of One's Own Speech Fluency in EFL.

\begin{tabular}{|c|l|c|c|}
\hline $\mathbf{N}$ & \multicolumn{1}{|c|}{ Frame } & Participants & Controls \\
\hline 1 & Communication & $11 \%$ & $37 \%$ \\
\hline 2 & Disfluency & $42 \%$ & $11 \%$ \\
\hline 3 & Grammar & $5 \%$ & $11 \%$ \\
\hline 4 & Importance & $16 \%$ & $47 \%$ \\
\hline 5 & Multimedia & $5 \%$ & $26 \%$ \\
\hline 6 & Role Model & $37 \%$ & - \\
\hline
\end{tabular}

Table 4 below illustrates the distribution of the frames that involve the participants' and controls' framing of speech fluency in EFL by primary school students.

Table 4. The Framing of EFL Students' Speech Fluency by the Participants and Controls.

\begin{tabular}{|c|l|c|c|}
\hline $\mathbf{N}$ & \multicolumn{1}{|c|}{ Frame } & Participants & Controls \\
\hline 1 & Communication & $5 \%$ & $11 \%$ \\
\hline 2 & Disfluency & $16 \%$ & - \\
\hline 3 & Importance & $32 \%$ & $26 \%$ \\
\hline 4 & Multimedia & $52 \%$ & $47 \%$ \\
\hline
\end{tabular}




\subsection{Discussion}

It is evident from Tables 2-4 that there are differences in the distribution of frames within the groups and between the groups of participants and controls. Arguably, these differences are indicative of the participants' and controls' views of speech fluency in EFL. As has been mentioned in the introduction, prior research in applied linguistics is characterised by two main approaches towards speech fluency, a broad approach and a narrow one (Bosker et al. 2012). To reiterate, the broad approach towards speech fluency in EFL is "equivalent to overall speaking proficiency" (Chambers 1997: 536) and the language mastery (Lennon 1990: 390) that are manifested in communication. The narrow approach is typically associated with the speaker's temporal organisation of speech, for instance, ease, flow, smoothness (Lennon 1990: 391), and the speed of speech delivery (Tavakoli 2010). Following the main research objectives of the study, further in the article the participants' framing is discussed from the narrow, broad, and teacher-specific approaches towards speech fluency in EFL. Concurrently with that, the differences in the framing of speech fluency in EFL between the groups of participants and controls are compared.

\subsubsection{The framing of the narrow approach}

Judging from the data, the participants' understanding of speech fluency appears to reflect the narrow approach that is represented by the frame Flow. Obviously, the notion of flow in the context of speech fluency refers to the narrow and broad approaches alike. However, the participants provide several statements that are associated with the narrow approach in the frame Flow, for instance i) "When I hear the word fluency, I automatically think of a way of speaking where the words float naturally, and there are few stops and breaks" (P 11); ii) "My understanding of the term speech fluency in EFL is when a person's way of speaking is smooth and reasonably quick, and he/she does not have to make many stops or pause a lot" (P 16); iii) "Speech fluency is to be able to speak a language confidently, with very few pauses" (P 9). Notably, only 16\% of the controls frame speech fluency in EFL within the parameters of the narrow approach in the frame Flow. Assuming that a substantial number of participants (32\%) tend to frame their view of EFL speech fluency via the narrow approach, this finding appears to be in contrast to Tavakoli and Hunter (2018), who report that ESL teachers in their study refer to speech fluency in the broad sense.

Whilst the frame Flow has been identified in the participants' and controls' framing of EFL speech fluency in general, the frame Disfluency seems to be a recurrent feature of the participants' framing of speech fluency in general, their own speech fluency, and their primary school students' fluency in EFL. These findings are illustrated in Figure 2 below: 


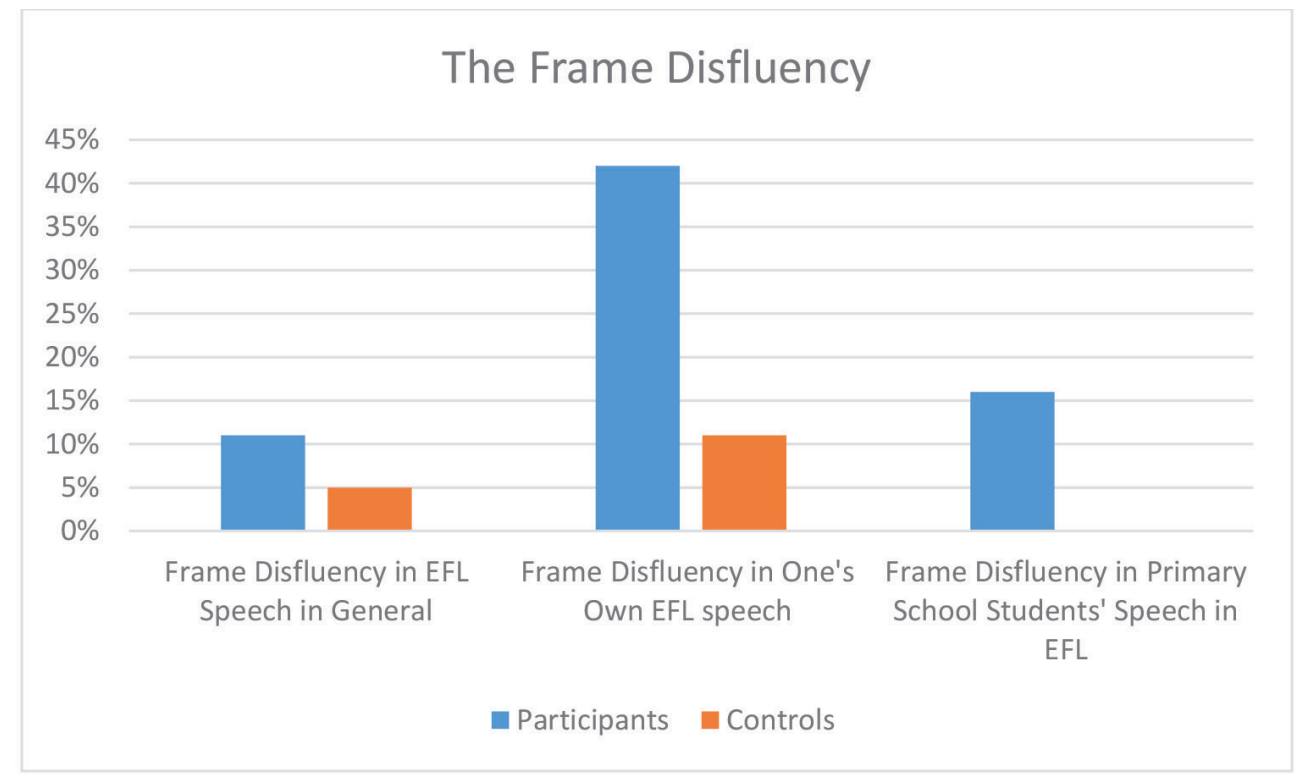

Figure 2. The Distribution of the Frame Disfluency.

It is evident from Figure 2 that the fame Disfluency appears to be associated, predominantly, with the participants' framing of their speech fluency in EFL. In this framing, the participants foreground those variables (typically, sounds of the English language) that cause disfluencies either in their own speech in EFL or the speech of their primary school students. For instance, several participants indicate that whilst their speech in English is fairly fluent, some disfluencies seem to compromise it. The participants typically refer to their disfluencies that are caused by those sounds of the English language that are absent from Norwegian, specifically the sound $[\theta]$ and the minimal pair $[\mathrm{z}] /[\mathrm{s}]$. In particular, one of the participants suggests that her disfluencies in EFL are associated with the $[z] /[\mathrm{s}]$ contrast that causes her "to think twice before I pronounce is [Iz] and was [wDz] and of course other words with s/z" (P3). Judging from the data illustrated by Figure 2, $42 \%$ of the participants provide statements that can be subsumed under the frame Disfluency. The same frame is also present in the participants' statements that refer to their primary school students' fluency in EFL. Specifically, one participant posits that "It can be difficult for the students to learn to speak English fluently. No matter how much they know about the English language, they will still face speech disfluencies" (P6). The participants ascribe primary school students' disfluencies in EFL to the differences between the phonological systems of English and Norwegian, and the insufficient oral skills of the students. Notably, the control group does not frame speech fluency of primary school students via the frame Disfluency. This finding can be taken to indicate that in-service teachers seem to be more aware of the difficulties faced by the primary school students in their acquisition of speech fluency in English.

It should be noted $21 \%$ of the participants (and none of the controls) frame their approach to speech fluency in EFL by the frame Vagueness. This frame is characterised by the participants' ambivalence towards the definition of speech fluency in 
EFL. Presumably, this ambivalent stance involves a continuum between the narrow and broad definitions of speech fluency. This frame can be further illustrated by the quote from the reflective essay written by the participant P15: "Speech fluency is rather vague and it is not clear to me which specific skills one must have in order to be defined as a fluent speaker" (P15).

\subsubsection{The framing of the broad approach}

As indicated in the introduction, the broad approach to speech fluency in EFL is associated with correct grammar and lexical diversity, idiomaticity, and native-like pronunciation (Götz 2013) that are indicative of overall speaking proficiency (Chambers 1997: 536). Arguably, the frames Communication, Grammar, Importance, Mastery, Multimedia, and Vocabulary pertain to the afore-mentioned broad view of speech fluency in EFL. The frame Communication is present in the participants' and controls' framing of EFL speech fluency in general, as well as in their own and primary school students' speech fluency in EFL. The frame Communication is illustrated by Figure 3 below.

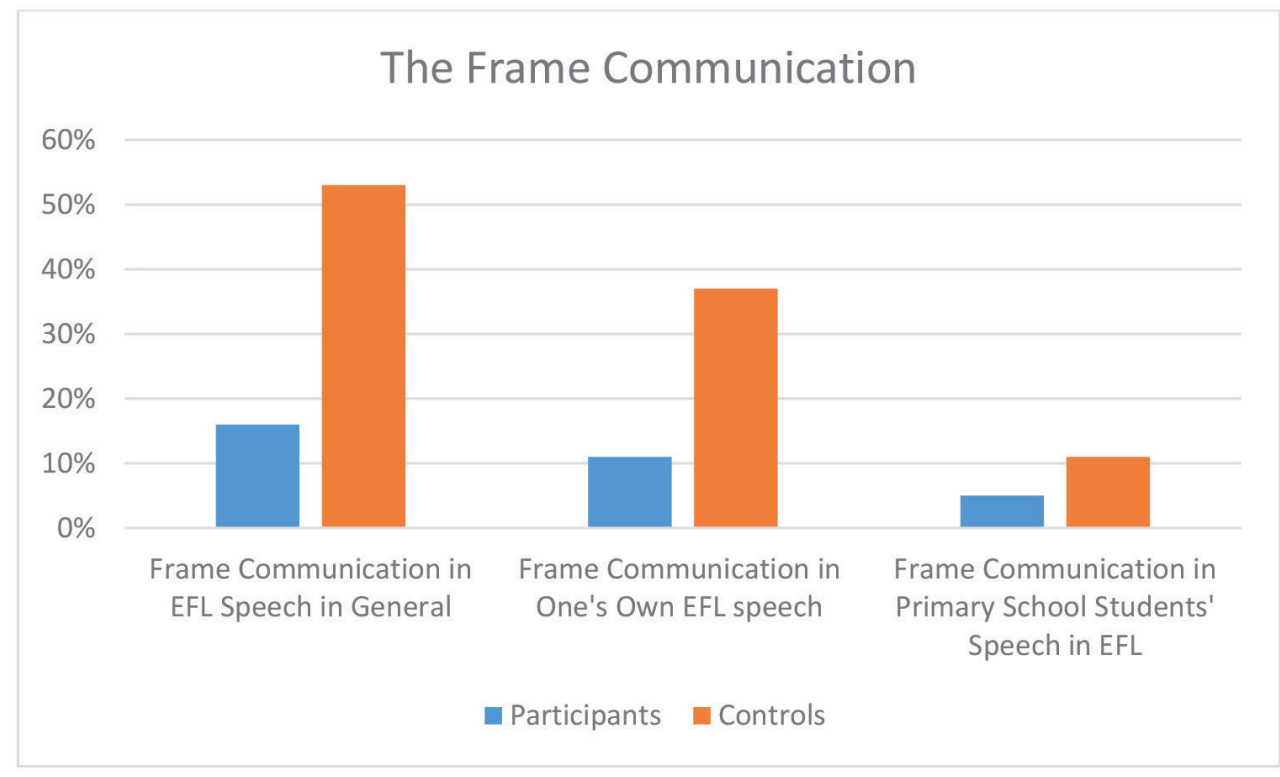

Figure 3. The Distribution of the Frame Communication.

The data exemplified by Figure 3 are suggestive of the participants' epiphenomenal focus upon communication in relation to speech fluency in EFL. In particular, only $16 \%$ of the participants appear to frame their understanding of speech fluency in EFL via the frame Communication, in contrast to $53 \%$ of the control group. However, reflecting upon speech fluency in EFL via the lenses of the frame Communication, the participants indicate that i) "Fluency is most importantly about communication, how able you are to communicate with others in another language than your own native 
language" (P11); ii) “... the most important thing is to make communication happen, to make ourselves understood and to use the English language with great enthusiasm" (P8). Notably, the controls, who are pre-service primary school teachers, seem to prioritise communicative aspects of speech fluency, especially when they regard speech fluency in EFL in general and their own speech fluency (see Figure 3). However, only $5 \%$ of the participants and $11 \%$ of the control group frame EFL primary school students' speech fluency by means of the frame Communication.

Similarly to the frame Communication, the frame Importance is present in the participants' and controls' framing of EFL speech fluency in general, as well as in their own and primary school students' speech fluency in EFL, as seen in Figure 4:

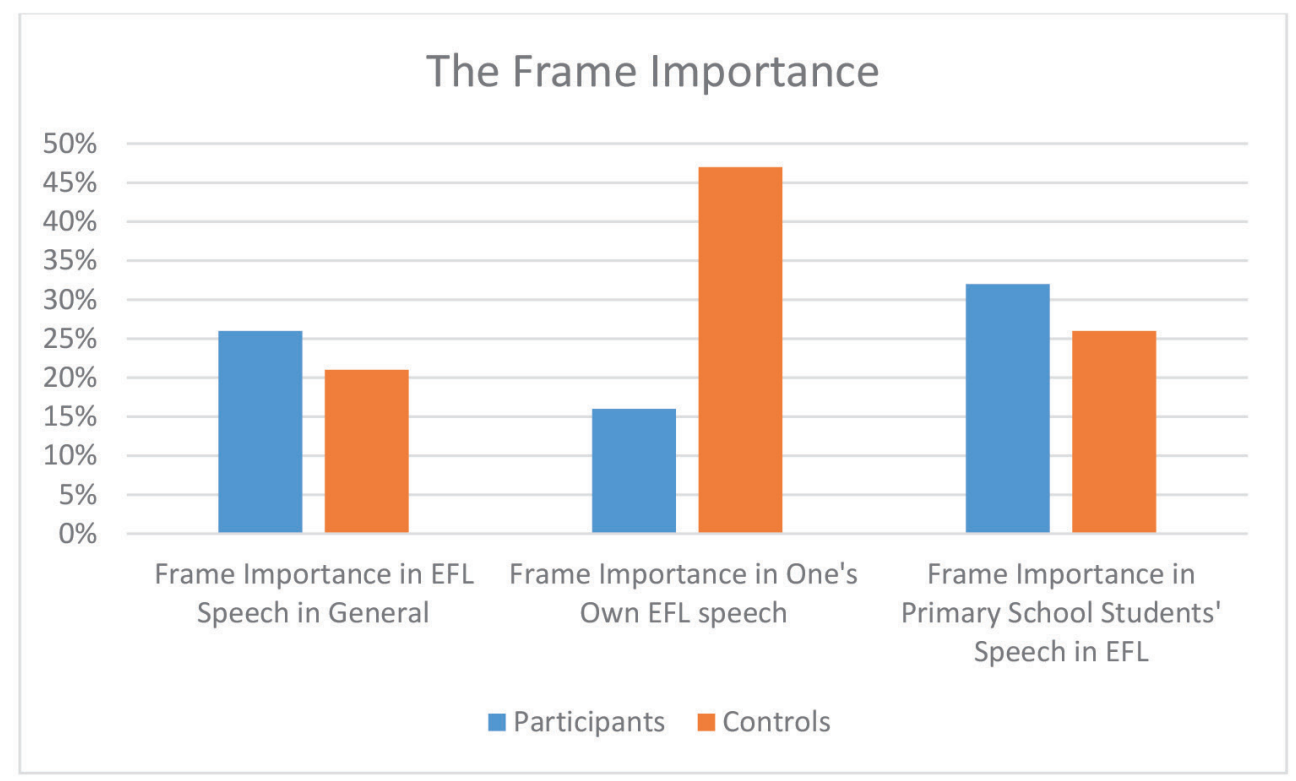

Figure 4. The Distribution of the Frame Importance.

It is observed in Figure 4 that the presence of the frame Importance in all three reference points of speech fluency, i.e. general, one's own, and EFL primary school students', is indicative of the participants' awareness of the role of speech fluency in EFL teaching and learning. This finding is in contrast with the study that has been conducted by Yang (2014), who indicates that Chinese L1 EFL in-service teachers appear to relegate the role of speech fluency in EFL to an epiphenomenal status. Additionally, the present finding differs in terms of the important role of speech fluency from the results reported by Tavakoli and Hunter (2018), who do not indicate that in-service ESL teachers in their study treat speech fluency as an important aspect of EFL teaching and learning. In the present study, however, the participants' attention to speech fluency is evident from their framing of primary school students' speech fluency in EFL, e.g. "For my students in the 5th grade I think that the role of fluency in the English language is important and perhaps even more important in today's global world than when I was at their age" (P7). 
Data analysis indicates that the frame Importance is present in the participants' and controls' framing of their own speech fluency in EFL, for instance, Participant P10 posits that "Fluency is very important for me. As a teacher, I should be fluent. If I am not fluent in English, it can affect my students" (P10). These findings lend indirect support to the previous research by Fuchs, Kahn-Horwitz, and Katzir (2019), who point to the important role of fluency in EFL. It is evident from Figure 4 that the participants and controls share the view of speech fluency as an important variable in the EFL teaching. However, the controls prioritise the importance of speech fluency in their own speech production in EFL (47\%).

Arguably, lexical, grammatical and syntactic areas of EFL proficiency could be treated under the aegis of broad fluency (Lennon 1990). In the present corpus, the frames Grammar and Vocabulary, respectively, appear to reflect the participants' view of speech fluency as an index of lexical and syntactic proficiency. Judging from the data, these frames are not equally distributed, as illustrated by Figure 5 .

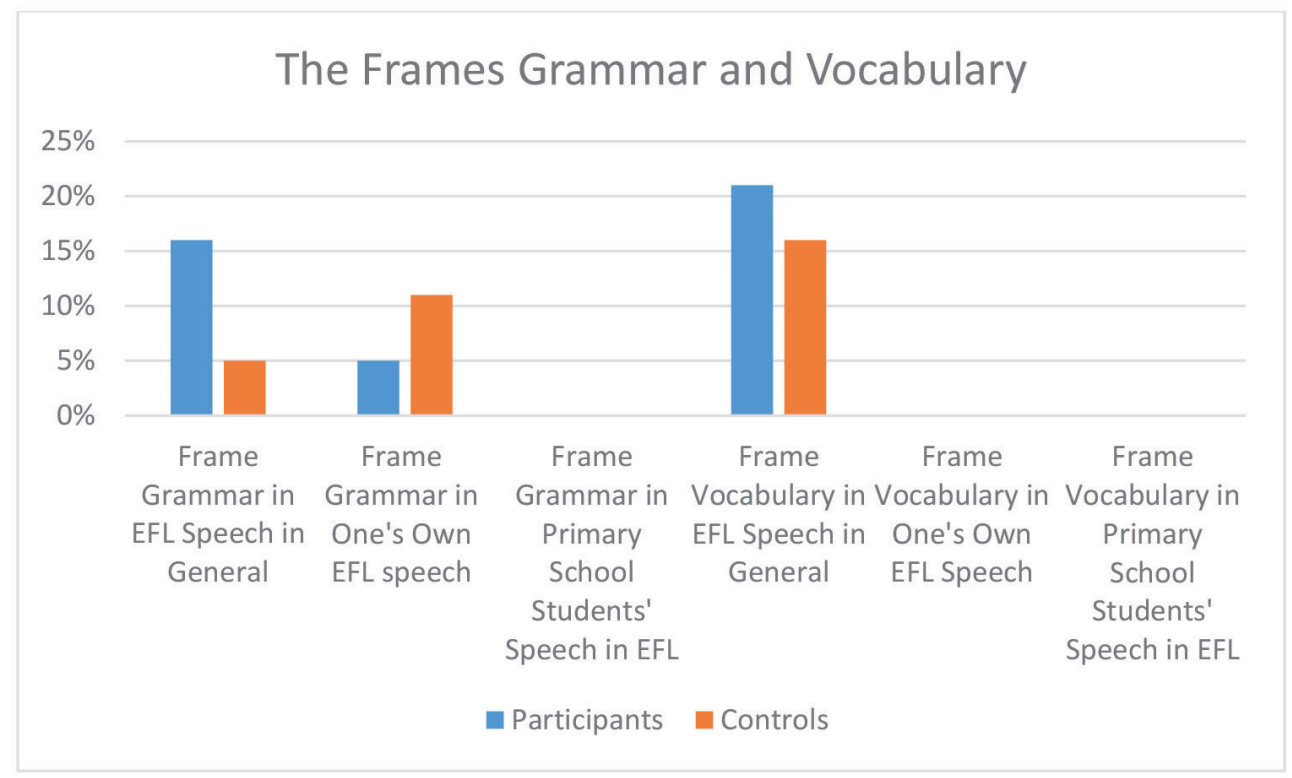

Figure 5. The Distribution of the Frames Grammar and Vocabulary.

It is evident from Figure 5 that the participants foreground the frame Grammar when they reflect upon speech fluency in EFL in general (16\%). For instance, participant P5 argues that "For me a fluent speaker has correct grammar, and creates a sentence without too much thinking". As far as the participants' speech fluency in EFL is concerned, the frame Grammar appears less frequently distributed (5\%), e.g. "My grammar can cause disfluency, especially with some of the verbs in past tense and concords. This might lead to more hesitations and perhaps also self-corrections" (P3). Notably, the frame Grammar is absent from the participants' and controls' reflections concerning primary school students' speech fluency in EFL (see Figure 5). Presumably, the absence can be explained by the participants' and 
controls' view of the nascent stage of grammatical abilities of primary school students.

Similarly, the frame Vocabulary is not present in the participants' and controls' framing of primary school students' speech fluency. Instead, the frame Vocabulary has been identified in the participants' and controls' framing of speech fluency in EFL in general. In the frame Vocabulary, the participants emphasise the importance of prior lexical knowledge, e.g. "As a teacher, I think it is important to have a good English vocabulary and good prior knowledge of English to be able to speak English fluently" (P5).

Assuming that the frame Multimedia involves references to vocabulary, lexical diversity, native-like accent and intonation, and the use of pragmatic features, it could be related to the broad approach to speech fluency (Bosker et al. 2012; Götz 2013). The frame Multimedia is conceived of by the participants and their respective controls as a space that facilitates the development of speech fluency in EFL, especially as far as primary school students' speech fluency is concerned. This finding is illustrated in Figure 6 below.



Figure 6. The Distribution of the Frame Multimedia.

Whilst the frame Multimedia is present in 5\% of the participants' reflections about their own speech fluency in EFL, $52 \%$ of the participants frame primary school students' speech fluency in EFL by means of the frame Multimedia. Similar findings have not been reported in previous research (see section 2 of this article). However, in the present data the frame Multimedia appears to be substantially represented, presumably, due to the fact that "Norwegian children of today are exposed to the English language everywhere, through films, video games, TV or YouTube clips" (P19). According to the participants, "multimedia became a part of their lives, and 
they are picking it up quite unconsciously. For young learners, the spoken language of the media is the medium through which they encounter, understand and learn English" (P6). Arguably, by means of construing speech fluency in EFL by the frame Multimedia, the participants and their controls refer to the construal of out-of-classroom exposure to the English language and its impact on speech fluency in EFL. As previously mentioned, the forms of exposure involve films, video games, and YouTube videos that play a facilitative role in the development of primary school students' fluency in EFL.

\subsubsection{The framing of the teacher-specific approach}

The frame Role Model appears to be specific to the group of participants. Notably, $37 \%$ of the participants construe their understanding of speech fluency via this frame. The analysis of research literature in EFL reveals that similar framing has not been identified in the prior studies mentioned in the introduction (e.g., Butler 2004; Tavakoli \& Hunter 2018; Yang 2014). The following quotes can further illustrate the frame Role Model, e.g. i) "...as an English teacher, I have to be fluent in English. My task as a teacher and role language model for my students is to speak fluently" (P2); ii) "I guess my role as a teacher in the 4th grade pushes me to think about what kind of role model I would like to be" (P3); and iii) "At work when I am together with my students, I am aware of that I am a role model for my students. Therefore, it is important for me that I work on my speech fluency" (P16). It is evident from these quotes that the participants equate their speech fluency in EFL with the identity of a role model.

It has been assumed in the present study that the participants' enrollment in the in-service EFL course that is concurrent with their EFL teaching at primary schools would facilitate the creation of a specific combination of experiences, which, in turn, would map onto the participants' framing of speech fluency in EFL. Presumably, the frame Role Model is reflective of the teacher-specific view of EFL fluency in the sense that is associated with the marker of their social identity (Kristiansen 2001) of an EFL teacher. Furthermore, the frame Role Model could potentially reflect the participants' high expectations of themselves in terms of speech fluency in English. Arguably, this finding provides a possible explanation of the participants' framing of their own speech fluency in English via the frame Disfluency (see section 3.5.1). The frame Disfluency reflects the participants' self-criticism regarding their speech fluency. To reiterate, $42 \%$ of the participants frame their speech fluency in EFL via the frame Disfluency. Arguably, there is an implicit correlation between the high occurrence of the frames Role Model and Disfluency, since the participants exhibit awareness of the importance of speech fluency in EFL and the need to be fluent in English as a token of the role model, who by default should not be disfluent.

As evident from the frame Role Model, the participants approach speech fluency in EFL through the lenses of an EFL teacher, who should speak English fluently. Presumably, such framing is evocative of the teacher-specific sociocultural frames that have been observed by Pennington and Hoekje (2014). Assuming that sociocultural frames in the sense by Pennington and Hoekje (2014) involve cultural and historical contexts and practices, it seems possible to argue that the participants' framing of speech fluency via the frame Role Model is suggestive of performing a 
role of an EFL teacher who is a fluent speaker of English. Arguably, the sociocultural context in Norway would facilitate a societal expectation of an EFL teacher to be fluent in the English language. Obviously, this assumption should be verified in a separate study that would involve primary school students' as well as their parents' expectations associated with a primary school teacher's speech fluency in English.

\section{Conclusions}

The article discusses a mixed-method study of how the participants frame their understanding of speech fluency in EFL. The framing analysis in the study has yielded several frames that are employed by the participants to construe their view of speech fluency in EFL. These frames are Communication, Disfluency, Flow, Grammar, Importance, Multimedia, Role Model, Vagueness, and Vocabulary. The control group frames their understanding of speech fluency in EFL by qualitatively similar frames, such as Communication, Disfluency, Flow, Grammar, Importance, Multimedia, and Vocabulary. However, it is observed that the frame Role Model appears to be specific to the participants.

Judging from the results, it seems pertinent to conclude that the participants frame their understanding of EFL speech fluency in general by means of the frames Communication, Disfluency, Flow, Grammar, Importance, Vagueness, and Vocabulary. It should be noted that the participants' most frequent framing of EFL fluency, in general, involves the frame Flow. Given the co-occurrence of the frames Flow and Importance, it could be generalised that the participants exhibit a substantial degree of awareness of speech fluency in EFL, which they regard, predominantly, in the narrow sense.

The data indicate that the participants construe their own speech fluency in EFL via the frames Communication, Grammar, Importance, Multimedia, and Role Model. It could be posited that the participants apply a broad perspective to frame their speech fluency in EFL. Taking into consideration that the frames Disfluency (42\%) and Role Model (37\%) are the most frequently used frames in the participants' framing of their own speech fluency, it could be assumed that speech fluency emblematises the participants' awareness of speech fluency as a token of an EFL teacher, who is expected to be fluent by a variety of stakeholders (for instance, students, parents, authorities, the system of education, etc.).

The results of the data analysis reveal that the participants frame their primary school students' speech fluency in EFL via the frames Communication, Disfluency, Importance, and Multimedia. Given that the participants seem to prioritise the frame Multimedia (52\%), it can be assumed that they are aware of the role of mass media in primary school students' speech fluency development in EFL.

Summarising the present findings from a linguo-didactic perspective, it appears possible to generalise that the participants exhibit awareness of the important role of speech fluency in EFL and critically self-assess their own speech fluency. The participants' emphasis on the framing of an EFL teacher as a fluent speaker is in contrast to the control group, where such framing is not identified. It could be concluded that the framing of speech fluency via the lenses of the frame Role Model is reflective of the participants' professional attitude towards EFL teaching and learning. 


\section{Acknowledgements}

The author of the article would like to acknowledge the participants and their respective controls, whose participation is invaluable and highly appreciated. The author is very appreciative of the editors and the anonymous reviewers for their suggestions and advice.

\section{References}

Bergmann, Christopher, Simone A. Sprenger, \& Monika S. Schmid (2015). The impact of language co-activation on L1 and L2 speech fluency. Acta Psychologica, 161, 25-35.

Bernstein, Basil (2018). On the classification and framing of educational knowledge. In Richard Brown (ed.), Knowledge, education, and cultural change (pp. 365-392). London: Routledge.

Bosker, Hans R., Anne-France Pinget, Hugo Quené, Ted Sanders \& Nivja de Jong (2012). What makes speech sound fluent? The contributions of pauses, speed and repairs. Language Testing, 30, 2: 159-175.

Burgers, Christian, Elly A. Konijn, \& Gerard J. Steen (2016). Figurative framing: Shaping public discourse through metaphor, hyperbole, and irony. Communication Theory, 26,4: 410-430.

Butler, Yuko G. (2004). What level of English proficiency do elementary school teachers need to attain to teach EFL? Case studies from Korea, Taiwan, and Japan. TESOL Quarterly, 38, 2: 245-278.

Chambers, Francine (1997). What do we mean by fluency? System, 25, 4: 535-544.

Chong, Dennis, \& James N. Druckman (2007). Framing theory. Annual Review Political Sciences, 10: 103-126.

Council of Europe (2001). Council for Cultural Co-operation. Education Committee. Modern Languages Division. Common European Framework of Reference for Languages: learning, teaching, assessment. Cambridge University Press.

Dahl, Trine (2015). Contested science in the media: Linguistic traces of news writers' framing activity. Written Communication, 32, 1: 39-65.

Entman, Robert M. (1993). Framing: Toward clarification of a fractured paradigm. Journal of communication, 43, 4: 51-58.

Fillmore, Charles J. (2006). Frame semantics. Cognitive linguistics: Basic readings, 34: 373-400.

Fillmore, Charles J. (1979). On fluency. In C. Fillmore, D. Kempler, \& W.-Y. Wang (Eds.), Individual differences in language ability and language behavior (pp. 85-101). New York: Academic Press.

Fuchs, Stephanie, Janina Kahn-Horwitz, \& Tami Katzir (2019). Theory and reported practice in EFL literacy instruction: EFL teachers' perceptions about classroom practices. Annals of Dyslexia, 69, 1: 1-22.

Götz, Sandra (2013). Fluency in native and nonnative English speech. Vol. 53. John Benjamins Publishing.

James, Lori E., Brittany N. Chambers, \& Chelsea L. Placzek (2018). How scenes containing visual errors affect speech fluency in young and older adults. Aging, Neuropsychology, and Cognition, 25, 4: 520-534.

Kormos, Judit (2014). Speech production and second language acquisition. London: Routledge. 
Kormos, Judit, \& Mariann Dénes (2004). Exploring measures and perceptions of fluency in the speech of second language learners. System, 32, 2: 145-164.

Kristiansen, Gitte. (2001). Social and linguistic stereotyping: A cognitive approach to accents. Estudios ingleses de la Universidad Complutense, 9: 129-145.

Lennon, Paul (1990). Investigating fluency in EFL: A quantitative approach. Language Learning, 40, 3: 387-417.

Nilsen, Thor, \& Rugesæter, Kåre. N. (2015). English Phonetics for Teachers. Oslo: Fagbokforlaget.

Pennington, Martha C. (1999). Framing Bilingual Classroom Discourse: Lessons from Hong Kong Secondary School English Classes. International Journal of Bilingual Education and Bilingualism, 2, 1: 53-73.

Pennington, Martha C., \& Hoekje, Barbara J. (2014). Framing English language teaching. System, 46: 163-175.

Pennington, Martha C., \& Rogerson-Revell, Pamela (2019). Framing the Teaching of Pronunciation. In English Pronunciation Teaching and Research (pp. 119-172). London: Palgrave Macmillan.

Pinget, Anne-France, Hans Bosker, Hugo Quene, \& Nivja de Jong (2014). Native speakers' perceptions of fluency and accent in L2 speech. Language Testing, 31, 3: 349-365.

Rossiter, Marian J., Tracey Derwing, Linda Manimtim, \& Ron Thomson (2010). Oral fluency: The neglected component in the communicative language classroom. Canadian Modern Language Review, 66, 4: 583-606.

Safari, Parvin (2018). A critical reflection on (re)construction of my identity as an English language learner and English teacher. Professional Development in Education, 44, 5: 704-720.

Saito, Kazuya, \& Kim van Poeteren (2012). Pronunciation-specific adjustment strategies for intelligibility in L2 teacher talk: Results and implications of a questionnaire study. Language Awareness, 21, 4: 369-385.

Sato, Masatoshi (2014). Exploring the construct of interactional oral fluency: Second Language Acquisition and Language Testing approaches. System, 45: 79-91.

Scott, Mike (2008). Wordsmith Tools: version 4.0.

Segalowitz, Norman, \& Barbara F. Freed (2004). Context, contact, and cognition in oral fluency acquisition: Learning Spanish in at home and study abroad contexts. Studies in Second Language Acquisition, 26, 2: 173-199.

Semino, Elena, Zsófia Demjén, \& Jane Demmen (2016). An integrated approach to metaphor and framing in cognition, discourse, and practice, with an application to metaphors for cancer. Applied Linguistics, 39, 5: 625-645.

Simensen, Aud M. (2010). Fluency: an aim in teaching and a criterion in assessment. Acta Didactica Norge, 4, 1: 1-13.

SPSS (2016). IBM SPSS Statistics for Windows, Version 24.0. Armonk, NY: IBM Corp.

Tavakoli, Parvaneh (2010). Pausing patterns: Differences between L2 learners and native speakers.” ELT Journal, 65, 1: 71-79.

Tavakoli, Parvaneh, \& Ann-Marie Hunter (2018). Is fluency being 'neglected' in the classroom? Teacher understanding of fluency and related classroom practices. Language Teaching Research, 22, 3: 330-349.

Torgersen, Eivind N. (2018). Teaching Pronunciation. In Teaching and Learning English, edited by Henrik Bøhn, Magne Dypedahl and Gro-Anita Myklevold (pp. 215-230). Oslo: Cappelen Damm Akademisk.

Yang, Yingjie I. (2014). Is speaking fluency strand necessary for the college students to develop in the EFL class? Theory and Practice in Language Studies, 4, 2: 225-231. 